\title{
Knowledge, Attitude and Practice of Periodic Screening of Diabetes Mellitus among Teachers in Tikrit City in Iraq
}

\author{
Mayada Kamel Mohammed ${ }^{1}$, Maysaloon Ahmed Khudhair², Nisreen Mohammed Ibraheem³, \\ Afnan Alaa Abdul Rahman ${ }^{4}$, Aya Hussein Saher ${ }^{4}$, Fatin Aaffaa Aldeen Kasim ${ }^{4}$ \\ ${ }^{1}$ Lecturer, ${ }^{2}$ Assist Lecturer, ${ }^{3}$ Prof., ${ }^{4}$ Rotater, Department of Family and Community Medicine, \\ Tikrit Medical College, Tikrit University, Iraq
}

\begin{abstract}
Background: One of the most prevalent chronic diseases isDiabetes mellitus that have adverse effect on the health, and the goal today being placed on disease prevention, controlling and screening.

Aim: To assess knowledge, attitude and Practice of periodic screening of DM among teachers in Tikrit city.

Subject and Method: The study is a cross-sectional study that had conducted from 1st of November 2018 until 30 of March 2019 on teachers in Tikrit city primary and secondary school using a questionnaire.

Results: The knowledge regarding the diabetes and its screening a $24 \%$ were good and $46 \%$ were accepted regarding the disease symptoms and about its control $84 \%$ mention that diet modification is the best way then exercise and medication in lower percent while regarding complications $68 \%$ (much of them) knowledge were bad, About the importance of periodic screening the great percentage was yes.

Conclusion: There was $93.3 \%$ who have knowledge about diabetes mellitus screening among school teachers. Teacher's method for controlling diabetes mostly are diet modifications $84 \%$ then exercise $42.5 \%$.
\end{abstract}

Keywords: Diabetes mellitus awareness, School Teachers, Tikrit.

\section{Introduction}

Improvement of the population health depend ondisease prevention which is now consider as a superior strategy to decline the morbidity and mortality of most types of diseases ${ }^{[1]}$. Diabetes mellitusType 2 has become wide epidemic with markeddeformity,premature death and many medical problems ${ }^{[2]}$. DM is a non-infectious disease of public health importance which have a great effect on the life quality. Prevention and control can beobtained by improving the knowledge ${ }^{[3]}$. The aim of screening is to discover asymptomatic individuals

\section{Corresponding Authors:}

Dr Mayada Kamel Mohammed

Lecturer, Department of Family and Community

Medicine, Tikrit Medical College, Tikrit University,

Iraq

e-mail: drnihadkhalawe@gmail.com who are likely to have diabetes. The prevalence of diabetestype 2 is raisedstrongly ${ }^{[4,5]}$.

DM considerdangerous and life-threatening problems, butmay be treatedby proper managing and prevention. Diabetic self-care training and education considerimportant in the controlling of $\mathrm{DM}^{[6]}$. Non-controlled diabetes mayend with blindness, limb removal, kidney problems, and vascular and IHD. Screening test to the patients before features appearancemay lead to early detection and control, as the same time have no role in reduction of end-organ damage rates ${ }^{[7]}$. Many studies on (KAP) of diabetes have been supportthe needs for prevention, detection, and controlling ofdiabetic risk factor ${ }^{[8]}$. Good education and healthprogrammersdevelopment can lead to improvement of the patients knowledge and alter their practice $^{[9,10]}$. Cross-section study about the KAP of DM in Saurastha region, India revealed that poverty, low level of education have theresponsibilityof low level knowledge about DM. ${ }^{[11]}$ 
Dailyresearchesabout diabetics in India have been find meager levels of education and awareness about diabetes and very bad self-care method ${ }^{[12][13]}$. Thus, the elevatednumber of undetected cases, as well as thelow level of knowledgeand practices, has direct effect inincreasing sudden deaths, costly complications, and financial burdens ${ }^{(14,15)}$.

Aim of the Study: This study was conducted to assess the knowledge, attitude, and practice of periodic screening of diabetes mellitus among teachers in Tikrit city.

\section{Objectives of the Study:}

1. Identify the knowledge of teachers about importance of periodic checking and the source of their knowledge.

2. Clarify the knowledge about diabetes mellitus and its complications.

3. Demonstrate the practice of teachers for checking their blood sugar levels.

4. Identify the changes in life style among diabetic patients.

\section{Subjects and Method}

Ethical and Approval Consideration: Permission was taken from the teachers to fill the information and they were assured regarding the confidentiality of their responses.

Type of Study: The study is a cross-sectional study that had conducted from 1st of November 2018 until 30 of March 2019. The study was performed among teachers in Tikrit city primary schools (Al Kansa'a School and Al Noor School) and secondary schools (Al Motamizat School, Al Motamizen School, Al Safa School, Science City School and Al Forqan School). Sample:- Sample was chosen by clustered sampling then simple random sampling and the sample include 120 teachers from Tikrit city.

Questionnaire and Interview: The questionnaire used for data collection was designed in Arabic language.
It include demographic characteristics of teachers, followed by close ended and open questions related to their knowledge, attitude and practice of periodic screening for diabetes mellitus. It was administered by the teachers themselves.

Presentation and data analysis: All data management and analysis done by manual statistical method. Data was represented by suitable tables and figures which was designated by computer programs.

\section{Results}

knowledge of the teachers about the importance of screening of diabetes mellitus a show higher percentage $93.3 \%$ of them show very good knowledge while $6.66 \%$ were not well fig (1). The teachers knowledge regarding the disease itself and its symptoms, the results was the following, 25\% were good, $45.83 \%$ were accepted and 29.16 were bad fig (2).Good knowledge about importance of testing they mention that the source of their knowledge was by doctor counseling $46.66 \%$, media $29.16 \%$, internet $36.66 \%$ and $2.5 \%$ were by attending a seminar about the disease fig (3). Teachers knowledge about the complications of the diabetes $14.16 \%$ of the results of their responses were good which is very small percentage, about 17.5 were accepted and 68.33 were bad fig (4). The result of performing of their periodic screening test of diabetes came as $48 \%$ performing the screening test while $52 \%$ not which is a high percent, About the method or the test types they used to check their blood sugar, $65 \%$ respond with laboratory tests, $42.5 \%$ with home devices and $12.5 \%$ show that they don't do tests . The teacher's attitude toward the best method of controlling diabetes were $42.5 \%$ by regular exercise, $84.16 \%$ by diet modifications, 24.16 by medication, and $2.5 \%$ show that they don't know fig (5).Regarding the counseling and its role in raising the importance of knowledge about the periodic screening of diabetes mellitus,,In the table (1) show the general knowledge of the teachers about the disease and its aspects of treatment and the results came with variable responses. 


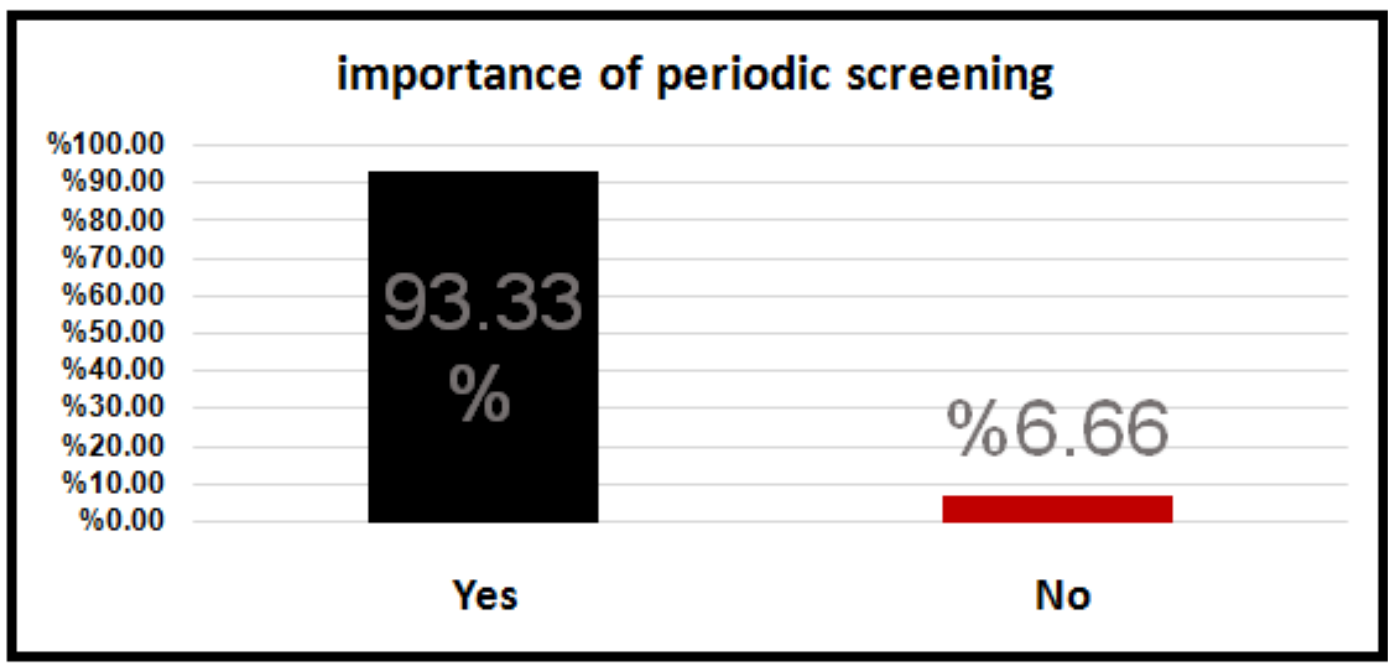

Figure (1): Knowledge of teachers in Tikrit city about the importance of diabetes mellitus screening

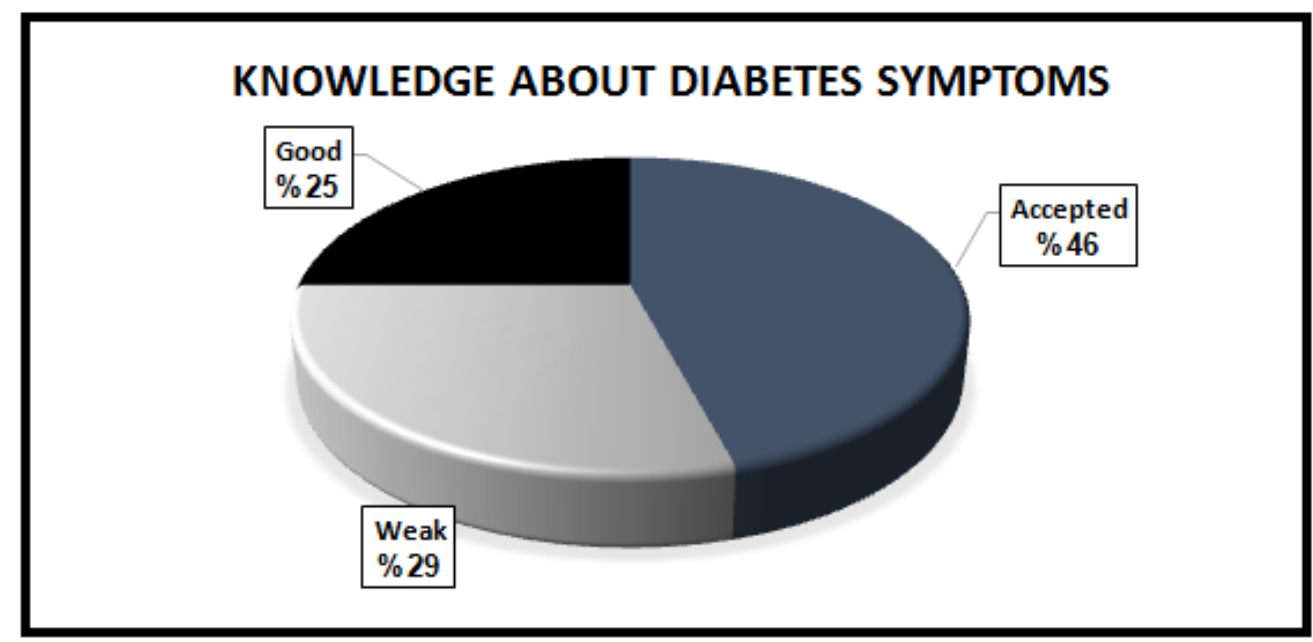

Figure (2): Knowledge of teachers in Tikrit city about diabetes mellitus symptoms.

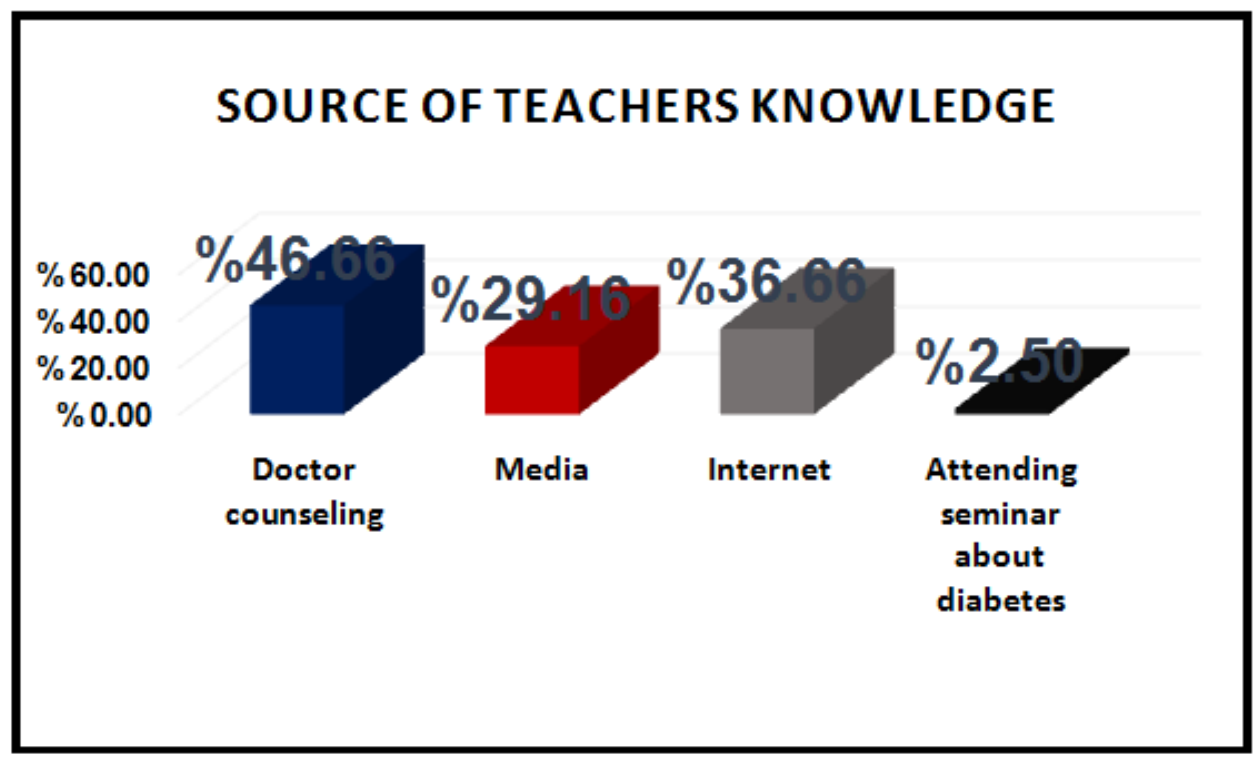

Figure (3): Source of knowledge of teachers in Tikrit city about the importance of diabetes mellitus periodic screening. 


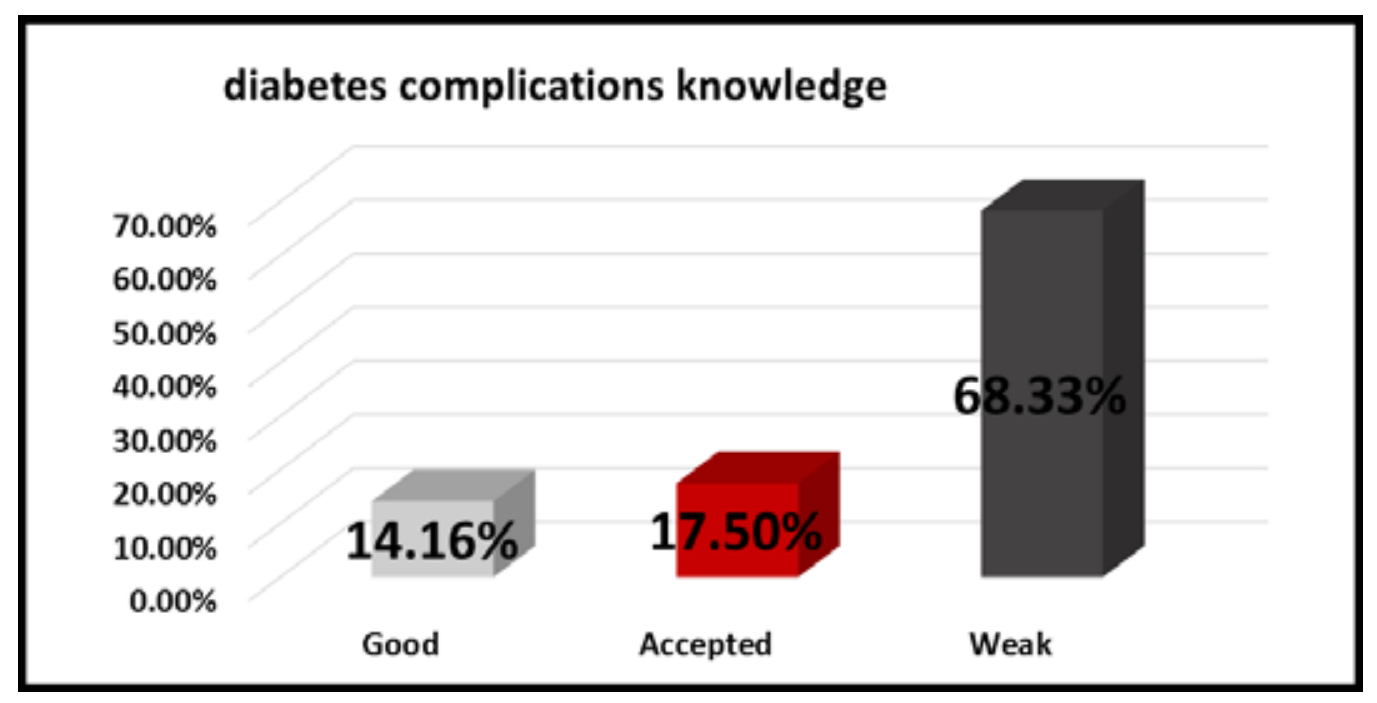

Figure (4): Knowledge of teachers in TIKRIT city about diabetes mellitus complications.

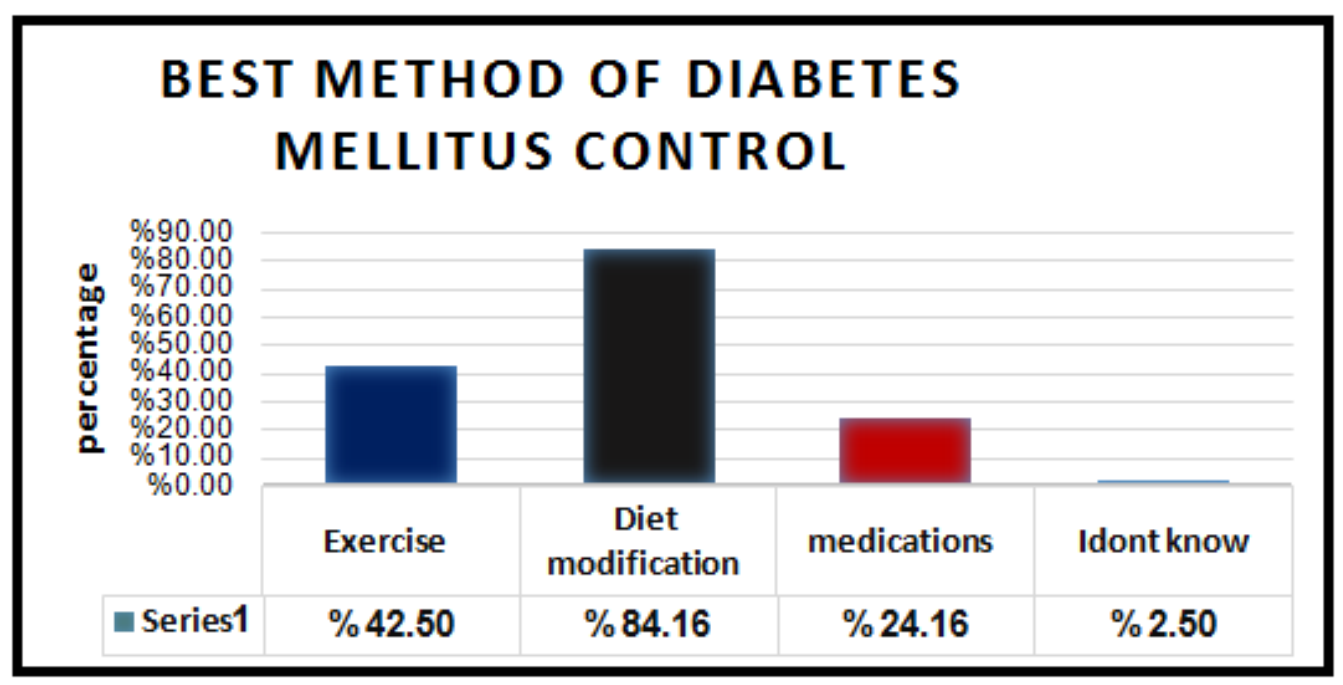

Figure (5): Diabetes mellitus controlling method among Tikrit city teachers.

Table (1): Teachers overall concepts about diabetes.

\begin{tabular}{|l|c|c|c|c|}
\hline & Agree & Percentage & Disagree & Percentage \\
\hline Diabetes mellitus is treatable? & 60 & $50 \%$ & 60 & $50 \%$ \\
\hline Diabetes mellitus is treatable by diet and exercise? & 81 & $67.5 \%$ & 39 & $32.5 \%$ \\
\hline Can be treated by medications? & 76 & $63.3 \%$ & 44 & $36.66 \%$ \\
\hline Regular exercise can be helpful for control? & 90 & $75 \%$ & 30 & $25 \%$ \\
\hline Diabetes mellitus complications can occur if not treated well? & 111 & $92.5 \%$ & 9 & $7.5 \%$ \\
\hline
\end{tabular}

\section{Discussion}

The knowledge of the teachers in Tikrit city about the importance of periodic screening have higher percentage $93.3 \%$ of them show very good knowledge while in DebreTabor town, Northwest Ethiopia 20.8\% were strongly agreed and $32.1 \%$ were agreed, a total of $52.9 \%$, that people should be examined for diabetes mellitus, this showing better knowledge of teachers in Tikrit than in Ethiopia ${ }^{[16]}$. Tikrit teachers mention that the source of their knowledge was by doctor counseling $46.66 \%$, media $29.16 \%$, internet $36.66 \%$ and $2.5 \%$ were by attending a seminar about the disease. In India 
patients believed that they can get information regarding diabetes through Books/Periodicals $28.57 \%$ and $10.72 \%$ got information by internet and television, $3.57 \%$ by other sources while majority of patients $57.14 \%$ were not interested to get information ${ }^{[17]}$. Teachers knowledge regarding the disease itself and its symptoms, the results was the following, $25 \%$ were good, $45.83 \%$ were accepted and 29.16 were bad, in comparison with Galle discrete in southern Seri Lanka ${ }^{[16]}$ around $37 \%$ of the participants was categorized as having good level of knowledge ${ }^{(18)}$. Teachers knowledge about the screening and its benefits for the improvement of patient outcomes when detecting the disease earlier $40 \%$ were agreed and in West Bengal, India [19], $46.5 \%$ of diabetics patients and $35.5 \%$ of non-diabeticsconsider that diabetes can be preventable, but $31.9 \%$ of diabetics patients and $14.1 \%$ of non-diabeticsconsider that DM can be controlled nottreat, indicating that early detection can help with the prognosis.Teachers knowledge about the complications of the diabetes $14.16 \%$ of the results of their responses were good which is very small percentage, about 17.5 were accepted and 68.33 were bad, while in study from Tabuk City, ${ }^{[20]}$ about information of teachers about DM complications, the teachers had good knowledge and more appropriate answers.

The practice of teachers in Tikrit city about the performing of their periodic screening test of diabetes and the results was $48 \%$ performing the screening test while $52 \%$ not which is a high percent after that asked the teachers about the method or the test types they used to check their blood sugar, $65 \%$ respond with laboratory tests, $42.5 \%$ with home devices and $12.5 \%$ show that they don't do tests ${ }^{[21]}$. The teacher's attitude toward the best method of controlling diabetes were $42.5 \%$ by regular exercise, $84.16 \%$ by diet modifications, 24.16 by medication, and $2.5 \%$ show that they don't know while in Study conducted in in DebreTabor Town, Northwest Ethiopia ${ }^{[16]}$ statethat insulin treatment $(57.3 \%)$, healthy diet $(56 \%)$ and oral tablets were the main ways of management of diabetes mellitus and regular exercise (32.5\%).

About the general overall view of teachers toward the disease and its controlling ways, asked some questions to assess their point of view and by comparing this with other countries results we found that in teachers of Tikrit city $50 \%$ of teachers showed by their answers that diabetes cannot be treated, while $51.3 \%$ of people in DebreTabor town ${ }^{[21]}$, Northwest Ethiopia were agreed that diabetes mellitus is not curable disease, nearly same percentage of knowledge regarding the disease. Regarding comparison of results about the knowledge regarding diet $67.5 \%$ of the Tikrit teachers were agreed that diabetes can be treated by diet modification, while $56 \%$ of the people of DebreTabor town, Ethiopia ${ }^{[16]}$ were agreed that practicing healthy diet is beneficial for controlling diabetes. In another study, $78 \%$ of population in Pakistan ${ }^{[18]}$ was agreed that controlling sugar will control diabetes. Showing better results of knowledge in Tikrit than Northwest Ethiopia, but Pakistan results were the best. And regarding exercise, in our study $75 \%$ were agreed that it can control diabetes, in Pakistan population $73 \%$ thought that exercise is helpful to prevent diabetes, thus the results are nearly the same ${ }^{[18]}$. The knowledge regarding treatment in comparison with other studies $63.3 \%$ of them thought diabetes is treatable with medications (tabs and injections) while $57.3 \%$ of DebreTabor town, Ethiopia ${ }^{[16]}$ people thought Insulin is petter for management of DM and $33.2 \%$ consider tablets are better for management of diabetes mellitus.

\section{Conclusion}

1. A high percentage $93.3 \%$ of teachers know the importance of the periodic screening of diabetes mellitus and their knowledge mostly $46.6 \%$ by doctor counseling.

2. The percentage of teachers who perform the periodic screening of diabetes is $48 \%$ and $65 \%$ of them do the screening in the medical laboratories.

3. Teacher's method for controlling diabetes mostly are diet modifications $84 \%$ then exercise $42.5 \%$.

Ethical Clearance: From research ethic committee in Tikrit university/college of medicine

\section{Source of Funding: Self}

\section{Conflict of Interest: Nill}

\section{References}

1. Knowledge, Attitude and Practice of Medical Checkup [Online]. 2008 Available from: https:// www.chp.gov.hk/files/pdf/kap_eng.pdf.

2. Wild S, Roglic G, Green A, Sicree R, King H. Global prevalence of diabetes: estimates for the year 2000 and projections for 2030. Diabetes Care. 2004; 27(5):1047-53.

3. Aturaka SO, Omotola O, Abiodun O, Imohi $\mathrm{P}$, Faturoti A. Knowledge of Risk Factors and 
Screening for Diabetes Mellitus among Youths in Southwestern Nigeria. American Journal of Health Research. 2017; 5(4):110-113.

4. Anna C. Type 2 diabetes: Awareness and screening in the community pharmacy setting. Journal of Diabetes Nursing. 2007; 11(4): 129.

5. Screening for type 2 diabetes: report of a World Health Organization and International Diabetes Federation meeting [Online]. 2008. 54 pg. Available from: URL: https://apps.who.int/iris/ handle/10665/68614.

6. Mensing C. Comparing the Processes: accreditation and Recognition. Diabetes Educ. 2010; 36:219-43.

7. Pippitt K, Marlana LI, GURGLE HE.Diabetes Mellitus: Screening and Diagnosis. 2016 Jan 15; 93(2):103-109.

8. Diabetes (online) 2018 (30 October 2018) available from: https://www.who.int/news-room/fact-sheets/ detail/diabetes.

9. International diabetes federation. Available from: https://www.idf.org/our-network/ regions-members/middle-east-and-north-africa/ members/36-iraq.html.

10. Kirkman MS, Briscoe VJ, Clark N, et al. Diabetes in older adults. Diabetes Care. 2012; 35(12):2650 2664.

11. Islam FMA, Chakrabarti R, Dirani $M$, et al. Knowledge, attitudes and practice of diabetes in rural Bangladesh: the Bangladesh population based diabetes and eye study (BPDES). PLoS One. 2014; 9(10):e110368.

12. Herath $\mathrm{M}$, Weerasinghe $\mathrm{N}$, WeerarathnaT. Knowledge, attitude and practice related to diabetes mellitus among the general public in Galle district in Southern Sri Lanka: a pilot study. BMC Public Health (2017) 17:535.

13. Z Saadia, S Rushdi, M Alsheha, H Saeed, M Rajab. A Study of Knowledge Attitude and Practices of Saudi Women towards Diabetes Mellitus. A (KAP) Study in Al-Qassim Region. The Internet Journal of Health. 2009 Volume 11 Number 2.

14. Shakibazadeh F, et al. Persian Diabetes selfmanagement education (PDSME) program: evaluation of effectiveness in Iran. Health promotion international; 2015. Pdav006.

15. Shayeghian $Z$, et al. the association between selfcare and control of blood sugar and health related quality of life in type II diabetes patients. Iranian Endocrinol Metab 2014; 15(6): 545-51.

16. Muche AA, Dadi AF. Knowledge and Attitude about Diabetes Mellitus and Its Associated Factors among People in DebreTabor Town, Northwest Ethiopia: Cross Sectional Study. Science Journal of Public Health. Vol.3 (2), 2015, pg. 199-209.

17. Gawand KS, Gawali UP, Kesari HV. A study to assess knowledge, attitude and practice concerning insulin use in adult patients with diabetes mellitus in tertiary care center. Indian Journal of Medical Research and Pharmaceutical Sciences 2016 Sept; 3(9). Pg. 38.

18. Gillani HA, Amirul Islam FM, Hayat $\mathrm{K}$, Atif $\mathrm{N}$, Yang C, Chang J, Qu Z and Fang Y. Knowledge, Attitudes and Practices Regarding Diabetes in the General Population: A Cross-Sectional Study from Pakistan. Int. J. Environ. Res. Public Health 2018, Sep 2. 15, 1906. Pg.7.

19. Munmun K, Subhranil S, Jogendra SA, Gurudev C, Shubhamoy G, Rajat C, Kaushik DD, Aloke G, Himangsu H, Rajarshi $M$, and Tanapa B. Knowledge, Attitude, and Practice Related to Diabetes Mellitus Among Diabetic and Nondiabetics Visiting Homeopathic. Hospitals in West Bengal, India. Journal of Evidence-Based Complementary \& Alternative Medicine [serial online] 2016, Vol. 21(1) 39-47.

20. Elbadawi A, Mahzari A, Alshahrani S, Alawaji $\mathrm{H}$, Khubrani A and Albalawi A. Knowledge and Attitude of School Teachers toward DM Complications in Tabuk City. International Journal of Health care Sciences, 2016: 4(2): 1742-1745.

21. Hrushikesh YR, D, Kumar A, Mallesh M, Purushothaman M. Significance of patient counseling in diabetes mellitus. World journal of pharmacy and pharmaceutical sciences. 9 June 2015; 4(8): 1215-1226. 